AL IBTIDA: JURNAL PENDIDIKAN GURU MI (2018) Vol 5 (1) : 69-82

DOI: http://dx.doi.org/ 10.24235/al.ibtida.snj.v5i1.2603

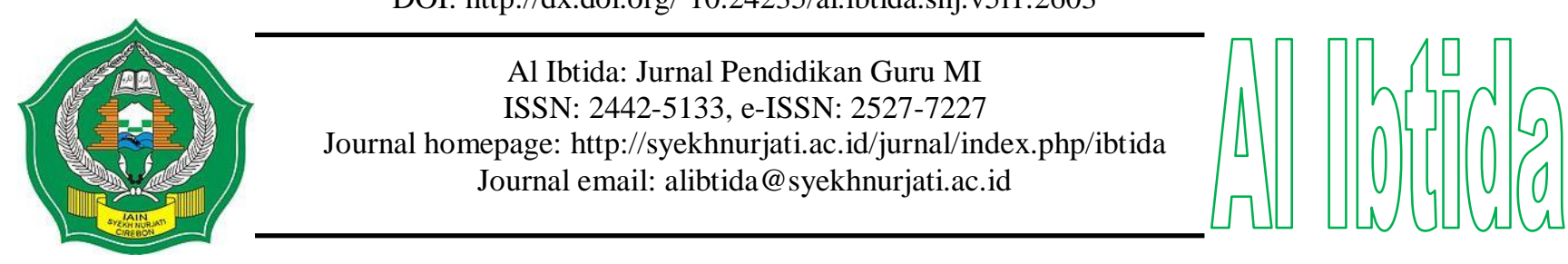

\title{
Pembelajaran Sains Berbasis Kearifan Lokal dalam Upaya Peningkatan Konservasi Lingkungan pada Mahasiswa PGSD di Batik Tulis Ciwaringin Cirebon
}

\author{
Nailah Tresnawati* \\ *Program Studi Pendidikan Guru Sekolah Dasar, Fakultas Keguruan dan Ilmu Pendidikan, \\ Universitas Swadaya Gunung Jati Cirebon \\ Email: nailahtresnawati@fkip-unswagati.ac.id
}

Received 19 April 2018; Received in revised form: 31 May 2018; Accepted 03 June 2018

Publish Online: 28 June 2018

\begin{abstract}
Abstrak
Nilai budaya asing berkembang semakin pesat seiring dengan kemajuan teknologi yang secara nyata telah menggeser nilai-nilai budaya lokal di Indonesia. Hampir sebagian masyarakat termasuk mahasiswa kurang mengetahui keunikan kearifan lokal yang ada pada daerahnya. Masyarakat menganggap pembelajaran sains di sekolah ataupun di kampus tidak berkaitan dengan budaya lokal di masyarakat. Tujuan dari penelitian ini adalah mengeksplorasi keunikan di kampung batik tulis ciwaringin terkait pemanfaatan sumber daya alam hayati sebagai pewarna alami dalam upaya meningkatkan konservasi lingkungan melalui pembelajaran sains berbasis kearifan lokal pada mahasiswa PGSD Unswagati Cirebon. Penelitian ini merupakan penelitian deskriptif kualitatif. Pengambilan data melalui observasi langsung, wawancara, lembar kerja mahasiswa. Subyek penelitian pada masyarakat blok Kebon Gedang desa Ciwaringin serta para perajin dan pengelola sentra batik tulis. Hasil penelitian menunjukkan bahwa terdapat berbagai jenis tumbuhan lokal yang digunakan sebagai pewarna alami di batik ciwaringin ini, baik dari akar, batang/kulit kayu, daun, bunga, buah, serta limbah kulit buahnya, kemudian melalui eksplorasi pengetahuan sains masyarakat (Indigineous knowledge) ini akan dihasilkan menjadi sebuah konsep-konsep sains, sehingga para mahasiswa mampu memperdalam pemanfaatan sumber daya alam (konsep sains) secara nyata, dan mengubah persepsi pengetahuan asli masyarakat yang terkesan sebagai pengetahuan budaya warisan saja, menjadi sebuah pengetahuan ilmiah yang dapat dipertanggungjawabkan. Pembelajaran sains berbasis kearifan lokal ini menumbuhkan kecintaan terhadap pengetahuan asli masyarakat sebagai bagian dari budaya bangsa yang berimplikasi terhadap konservasi sumber daya alam sekitar serta keseimbangan lingkungan.
\end{abstract}

Kata kunci: sumber daya alam hayati, batik tulis ciwaringin, kearifan lokal 


\begin{abstract}
The Foreign cultural values develop rapidly in line with advances in technology that has significantly shifted the values of the local culture in Indonesia. Most of the community including students are not informed about the uniqueness of local wisdom in the region. People consider that science learning in school or campus is not related to the local culture in society. The purpose of this study is to explore the uniqueness of the village of Batik Tulis Ciwaring related to the utilization of natural resources as natural dyes in an effort to increase environmental conservation through science teaching based on local wisdom to the PGSD students of Unswagati Cirebon. This research is a qualitative descriptive study. Data were collected through direct observation, interviews, and student worksheets. The objects of the research were Ciwaringin batik craftsman. The results show that there are different types of local plants used as natural dyes in batik Ciwaringin, both from the root, stem / bark, leaves, flowers, fruit, and fruit skin waste, then exploration of science knowledge society (indigenous knowledge) will be generated into a scientific concept so that the students are able to deepen the use of natural resources (scientific concepts) in real actions, and to change the perception of indigenous knowledge society appeared as knowledge of cultural heritage to be scientific knowledge that can be accounted for. Local wisdom-based science learning is to foster interests in the original knowledge of society as part of the national culture which affects the conservation of natural resources around as well as environmental balance.
\end{abstract}

Keywords: natural resources, batik tulis ciwaringin, local wisdom

\title{
PENDAHULUAN
}

Desa Ciwaringin terletak di bagian barat dari kota Cirebon berbatasan dengan kabupaten Majalengka, penduduk desa ini sebagian besar berprofesi sebagai petani, serta terdapat komunitas perajin batik tulis yang sangat ciri khas dibandingkan batik tulis lainnya di daerah Cirebon. Perkembangan batik Ciwaringin yang terletak di blok Kebon Gedang tumbuh sejalan dengan revitalisasi batik Trusmi (Casta, 2015). Menurut penuturan H. Fatoni (45 Tahun), proses penggunaan bahan alami dalam pewarnaan batik ini merupakan aktivitas kegiatan di pesantren Babakan Ciwaringin. Namun perkembangan pondok pesantren yang semakin pesat dan banyak santrinya, maka kegiatan membatik ini diserahkan kepada para perajin masyarakat lokal blok kebon Gedang desa Ciwaringin. Pengetahuan sains masyarakat lokal (indigenous science) dalam penggunaan bahan alami ini sebagai kearifan lokal yang unik dan juga sebagai perilaku masyarakat dalam menjaga keseimbangan lingkungan.

Pada kenyataannya globalisasi dan teknologi secara nyata telah menggeser nilai-nilai budaya lokal asli Indonesia. Berbanding terbalik dengan nilai budaya asing yang begitu berkembang pesat di dalam kehidupan masyarakat. Hampir sebagian para mahasiswa yang bertempat tinggal di blok Kebon Gedang desa Ciwaringin ini kurang mengetahui keunikan kearifan lokal pengetahuan sains masyarakat terkait penggunaan pewarna batik alami. Masyarakat memiliki anggapan bahwa pembelajaran sains di sekolah ataupun di kampus tidak berkaitan dengan budaya lokal di masyarakat sekalipun budaya bertani. Sehingga pembelajaran 
sains hanyalah sebuah materi hafalan yang tidak pernah dikaitkan ke dalam dunia nyata. Hal ini tidak sesuai dengan Permendikbud Nomor 57 tahun 2014 bahwa setiap siswa mampu menerapkan IPA secara bijaksana untuk menjaga dan memelihara kelestarian budaya.

Menurut Sudarmin dan Pujiastuti (2015) dalam penelitiannya menyatakan bahwa pengetahuan sains masyarakat berbasis budaya lokal dan kearifan lokal akan hal yang unik belum banyak diteliti, bahkan tidak pernah dimanfaatkan sebagai sumber belajar pada pembelajaran sains. Sementara itu, menurut penelitian yang telah dilakukan oleh Sudiana dan Surata (2010) mengungkapkan bahwa aspek budaya lokal dalam pembelajaran dapat meningkatkan efektivitas pada proses pembelajaran. Bahkan hasil penelitian Arfianawati, Sudarmin dan Sumarni (2016) mengungkapkan bahwa model pembelajaran kimia berbasis etnosains (MKPBE) dapat meningkatkan kemampuan kognitif dan berpikir kritis. Hasil penelitian Tresnawati (2017) tentang kerusakan biodiversitas mangrove menyatakan bahwa rendahnya persepsi siswa terhadap ekosistem mangrove dikarenakan kurangnya menghubungkan materi IPA di kelas dengan keadaan lingkungan sekitar dan budaya masyarakat. hal ini menyebabkan siswa tidak dapat mengeksplorasi kemampuan dalam mengenali lingkungan.

Terkait permasalahan di atas, maka perlu pembelajaran sains yang mengarahkan siswa melakukan sebuah pengamatan atau mengeksplorasi terhadap fenomena-fenomena alam sekitar, salah satunya melalui kearifan lokal. Kearifan lokal merupakan pengetahuan asli (indigineous knowledge) atau kecerdasan lokal (local genius) suatu masyarakat yang berasal dari nilai luhur tradisi budaya untuk mengatur tatanan kehidupan kesejahteraan masyarakat (Parmin, dkk., 2017). Kearifan lokal itu dapat berupa pengetahuan lokal, keterampilan lokal, kecerdasan lokal, sumber daya lokal, proses sosial lokal, norma-etika lokal, dan adat istiadat lokal (Parmin, dkk., 2017).

Oleh karenanya penelitian ini menerapkan pembelajaran sains berbasis kearifan lokal dalam perkuliahan materi dasar IPA melalui eksplorasi pengetahuan asli budaya masyarakat (indigineous knowledge) di batik Ciwaringin Cirebon terkait dengan materi pemanfaatan dan kerusakan sumber daya alam hayati untuk menumbuhkan rasa kecintaan terhadap pengetahuan asli sebagai bagian dari budaya bangsa yang berimplikasi terhadap konservasi sumber daya alam sekitar serta keseimbangan lingkungan. Pembelajaran sains berbasis kearifan lokal ini dilakukan melalui proses rekonstruksi sains asli di masyarakat. Rekonstruksi yang dimaksud adalah penerjemahan dari budaya yang ada di masyarakat dengan konsep sains yang ada (Parmin, dkk., 2017). Di mana yang dimaksud dengan sains asli adalah bagian dari kehidupan budaya masyarakat yang tetap dipertahankan karena mereka melihat dan mengalami sendiri berdasarkan pengalaman hidup (eksperimen alamiah) selama bertahun-tahun dari satu generasi ke generasi 
berikutnya melalui proses adaptasi dengan lingkungan alam maupun budaya dimana mereka berada (Suastra, 2005).

Eksplorasi masyarakat kampung batik tulis Ciwaringin terkait pemanfaatan sumber daya alam hayati sebagai pewarna alami dalam perkuliahan materi IPA dasar berbasis kearifan lokal ini mewujudkan salah satu visi dan misi Program Studi PGSD Unswagati, yaitu mengangkat nilai-nilai budaya dan kearifan lokal menuju jejaring global. Sehingga menumbuhkan kecintaan terhadap pengetahuan asli masyarakat sebagai bagian dari budaya bangsa yang berimplikasi terhadap konservasi sumber daya alam sekitar serta keseimbangan lingkungan.

\section{METODE PENELITIAN}

Jenis penelitian ini bersifat deskriptif kualitatif, yaitu menggambarkan dan mengeksplorasi pengetahuan asli masyarakat terkait pemanfaatan sumber daya alam hayati sebagai pewarna batik alami di batik tulis Ciwaringin kabupaten Cirebon sebagaimana adanya berdasarkan fakta-fakta yang tampak. Penelitian ini dilakukan pada masyarakat blok Kebon Gedang desa Ciwaringin serta para perajin dan pengelola sentra batik tulis selama satu bulan yang dimulai pada tanggal 28 Oktober 2017 s/d 30 november 2017.

Teknik pengambilan data secara observasi langsung, wawancara mendalam, studi kepustakaan, serta kajian artikel. Pembelajaran sains berbasis kearifan lokal ini diawali dengan sebuah eksplorasi serta rekonstruksi pengetahuan asli masyarakat kampung Ciwaringin yang dilakukan oleh mahasiswa semester I PGSD Unswagati Cirebon pada mata kuliah Materi Dasar IPA. Pada tahap eksplorasi mahasiswa melakukan penyusunan instrumen wawancara dan lembar observasi, selanjutnya mengobservasi beberapa bahan alami yang digunakan oleh masyarakat batik tulis Ciwaringin, identifikasi warna yang dihasilkan dari setiap bahan alam, dan pengaruh beberapa larutan fiksasi yang berbeda terhadap warna yang dihasilkan, serta praktek membatik dengan menggunakan bahan alami dengan beberapa larutan fiksasi yang berbeda. Kemudian fakta pengetahuan asli (Indigenous Knowledge) masyarakat kampung Ciwaringin tersebut direkonstruksi oleh mahasiswa menjadi pengetahuan sains (Indigenous Science) melalui kajian artikel ilmiah.

Adapun tahapan penelitian pembelajaran berbasis kearifan lokal eksplorasi kampung batik Ciwaringin pada materi dasar IPA terkait dengan pemanfaatan sumber daya alam hayati sebagai pewarna alami dapat disajikan pada gambar berikut: 


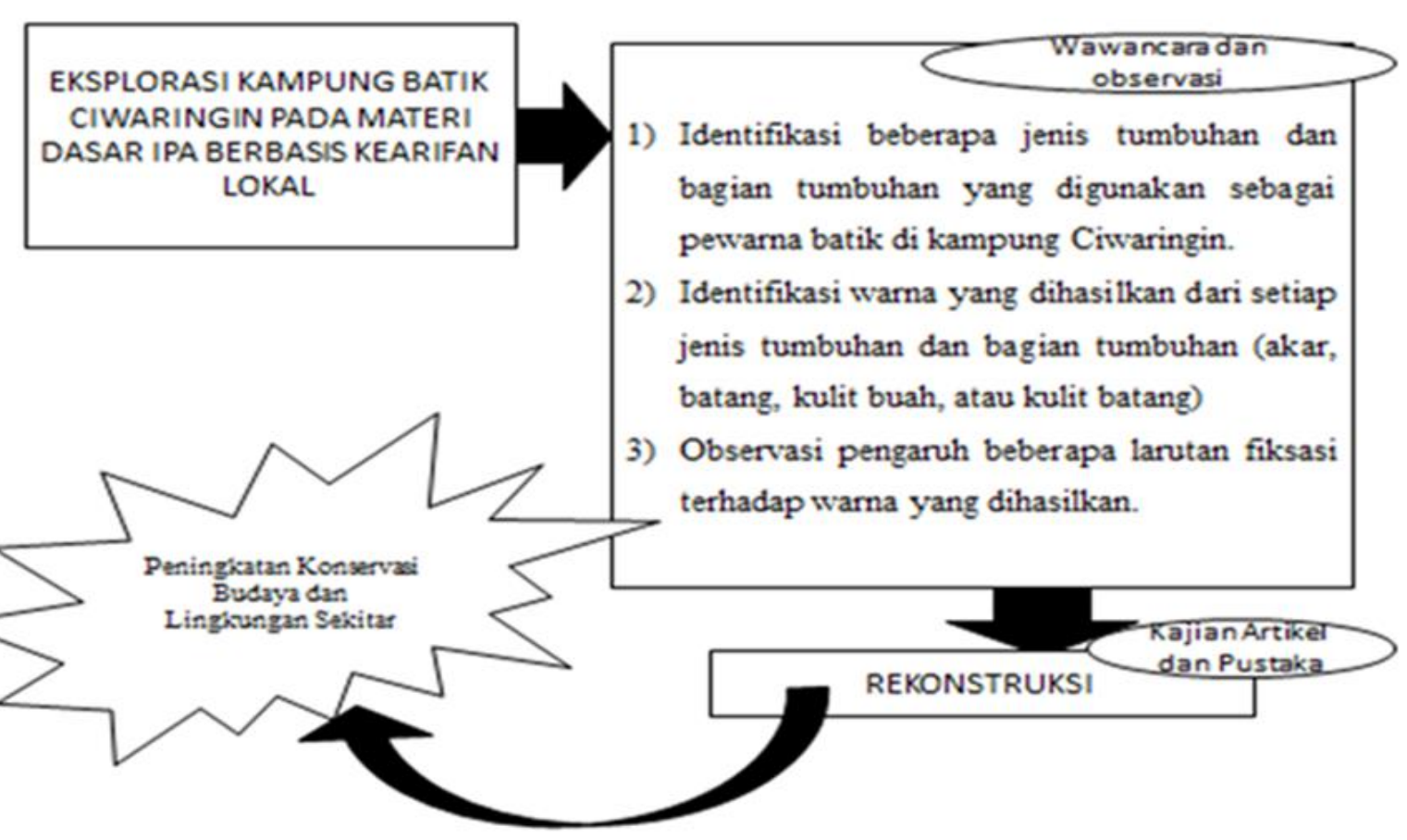

Gambar 1. Langkah- Langkah Penelitian

Dari gambar 1 di atas dapat dijelaskan bahwa langkah-langkah dalam penelitian ini terdiri dari 3 tahap, yakni tahap persiapan, tahap pelaksanaan (eksplorasi) dan tahap akhir (rekonstruksi). Pertama, tahap persiapan. pada tahap persiapan ini peneliti mengarahkan mahasiswa untuk mencari dan menghimpun informasi melalui studi kepustakaan dari berbagai artikel terkait objek pengetahuan asli masyarakat yang dituju. Selanjutnya peneliti menyusun lembar kerja mahasiswa (LKM) sebagai tujuan kegiatan yang akan dilakukan di sentra batik tulis. Kemudian peneliti menyusun instrumen studi lapangan berupa lembar wawancara dan observasi. Validasi lembar instrumen wawancara dan observasi dilakukan oleh pakar/dosen.

Kedua, tahap pelaksanaan (eksplorasi). Pada tahap pelaksanaan ini peneliti melakukan pengumpulan data dan informasi dengan mengamati objek secara langsung (observasi langsung dan wawancara mendalam) pada perajin dan pengelola sentra batik tulis serta masyarakat blok Kebon Gedang desa Ciwaringin kabupaten Cirebon. Kegiatan pengumpulan data dan informasi ini meliputi identifikasi beberapa jenis tumbuhan dan bagian tumbuhan yang digunakan sebagai pewarna batik di kampung Ciwaringin, identifikasi warna yang dihasilkan dari setiap jenis tumbuhan dan bagian tumbuhan (akar, batang, kulit buah, atau kulit batang) dan observasi pengaruh beberapa larutan fiksasi terhadap warna yang dihasilkan. Setelah melakukan pengumpulan data dan informasi, peneliti juga melakukan praktek membatik secara langsung dengan menggunakan pewarna alami dan beberapa bahan fiksasi yang berbeda.

Ketiga, tahap akhir (rekonstruksi). Pada tahap akhir ini peneliti menganalisis data hasil eksplorasi berdasarkan hasil observasi dan wawancara mendalam. Hasil analisis data eksplorasi 
berupa fakta pengetahuan asli masyarakat (indigenous knowledge) kemudian direkonstruksi menjadi pengetahuan sains (indigenous science) melalui analisis kajian artikel ilmiah dan pustaka. Setelah peneliti menganalisis data hasil eksplorasi, kemudian peneliti menarik kesimpulan dari hasil analisis tersebut.

\section{HASIL DAN PEMBAHASAN}

\section{A. Eksplorasi Masyarakat Kampung Ciwaringin}

Mengeksplorasi kearifan lokal di batik ciwaringin ini para mahasiswa melakukan observasi dan identifikasi secara langsung kepada kelompok perajin dan masyarakat kampung Ciwaringin. Adapun hal-hal yang diobservasi adalah terkait dengan jenis dan bagian tumbuhan yang digunakan menjadi bahan pewarna, identifikasi warna yang dihasilkan dari setiap jenis tumbuhan dan bagian tumbuhan, dan mengobservasi pengaruh beberapa larutan fiksasi terhadap warna yang dihasilkan. Selain itu, mereka juga melakukan praktek membatik, sehingga para mahasiswa mendapatkan hasil eksplorasi secara lengkap dengan fakta dan data. Melalui kegiatan tersebut mereka mampu membedakan keunikan pewarnaan batik di kampung Ciwaringin ini dengan pewarnaan batik sintesis di daerah lainnya (gambar 2a dan 2b).

Melalui kegiatan eksplorasi dalam pembelajaran berbasis kearifan lokal ini, para mahasiswa juga memiliki pengalaman langsung yang diharapkan dapat meningkatkan pemahaman terhadap pemanfaatan beberapa sumber daya alam hayati yang memang sudah dilakukan para nenek moyang kita sejak zaman dahulu. Hal ini dimaksudkan untuk menguatkan bahwa sains berkaitan dengan budaya masyarakat sehingga memunculkan rasa menghargai terhadap warisan budaya leluhur serta meningkatkan konservasi lingkungan sebagai potensi lokal wilayah kabupaten Cirebon. Hal ini sesuai pendapat Gondwe dan Nancy (2014) yang menyatakan bahwa integrasi pengetahuan budaya masyarakat ke dalam sebuah pendidikan di sekolah sangat bermanfaat terutama pada peningkatan kesadaran terhadap konservasi lingkungan.
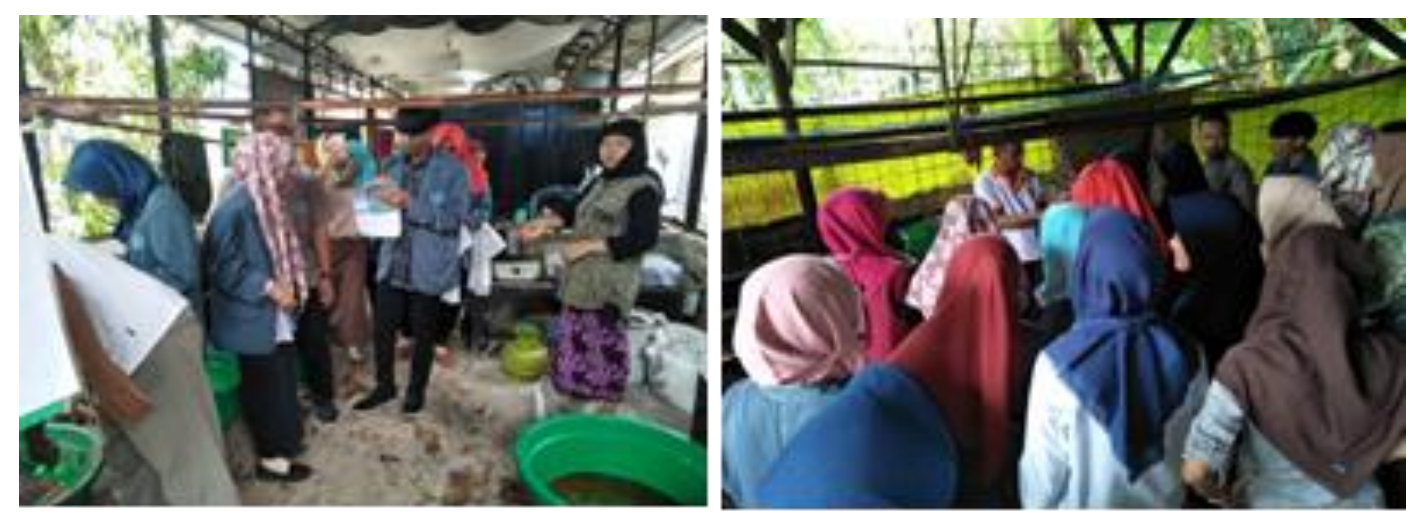

Gambar 2a. Kegiatan Eksplorasi Mahasiswa PGSD di Sentra Batik Tulis Ciwaringin 

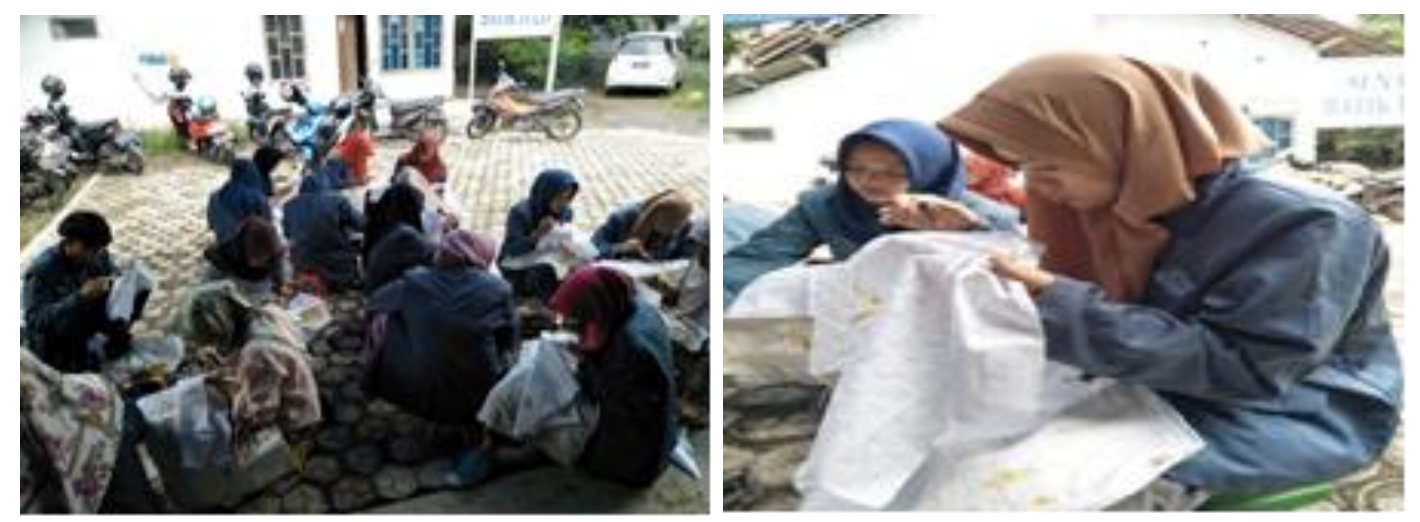

Gambar 2b. Kegiatan Eksplorasi Mahasiswa PGSD di Sentra Batik Tulis Ciwaringin

Konservasi lingkungan menurut Palmer (1994) ada tiga indikator, yaitu pengetahuan, sikap, dan keahlian. Kegiatan pembelajaran berbasis kearifan lokal ini mencakup pada ketiga indikator ini. Untuk indikator pengetahuan para mahasiswa mengeksplorasi sekaligus memiliki pengalaman yang menarik terkait pengetahuan budaya masyarakat dalam memanfaatkan sumber daya alam hayati menjadi pewarna alami batik, di mana hampir sebagian masyarakat Cirebon tidak mengenal budaya batik ciwaringin.

\section{B. Identifikasi Jenis Tumbuhan Sebagai Pewarna Batik di Kampung Ciwaringin}

Hasil eksplorasi melalui wawancara mendalam dan observasi mengungkapkan bahwa masyarakat kampung batik tulis Ciwaringin menggunakan beberapa jenis tumbuhan dan bagian tumbuhan dalam penggunaan pewarnaan pada batik tulisnya. Bagian tumbuhan yang digunakan mulai dari akar, kulit batang, daun, bunga, serta kulit buah. Adapun jenis tumbuhan yang digunakan oleh masyarakat kampung ini terdapat 8 jenis tumbuhan yang dapat dilihat pada tabel 1 dan gambar 3 bagian tumbuhan yang sudah dikeringkan. Menurut hasil wawancara mendalam dengan pak H. Fatoni (45 tahun) sebagai pengurus sentra batik tulis ini menyatakan bahwa jenis tumbuhan yang digunakan berasal dari beberapa tumbuhan lokal yang ada di wilayah Cirebon, seperti kulit kayu mangga, kulit buah rambutan, kulit jengkol, kulit manggis, akar mengkudu, serta kulit nangka, kecuali daun Indigo yang didapat dari Solo atau Yogyakarta.
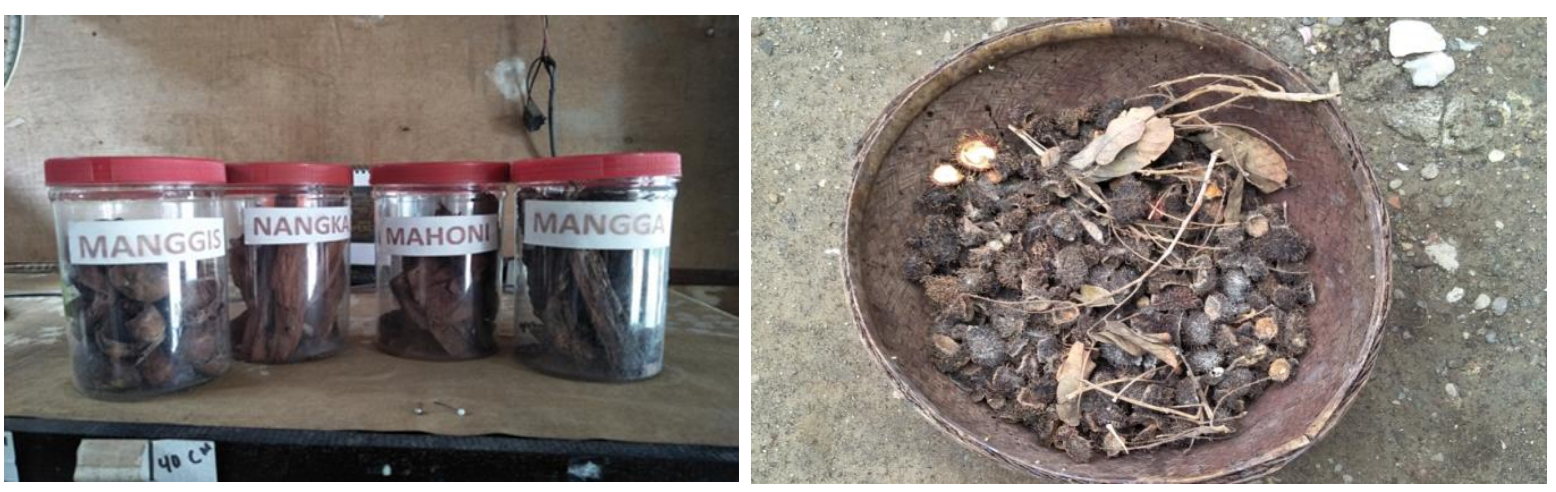

Gambar 3. Beberapa contoh sumber pewarna bahan alami 
Masyarakat kampung Ciwaringin ini memanfaatkan limbah dari beberapa jenis tumbuhan baik tumbuhan lokal maupun yang berada di luar kota dan kabupaten Cirebon. Hal ini merupakan sebuah konsep pemanfaatan limbah untuk mengurangi kerusakan lingkungan serta meminimalisir jumlah sampah organik yang semakin meningkat. Budaya asli masyarakat ini sangat berkaitan dengan konsep sains dalam pelestarian lingkungan, dimana nenek moyang terdahulu sudah mengenal konsep daur ulang limbah dan konservasi terhadap potensi lokal yang harus dilestarikan di daerahnya. Budaya asli masyarakat ini dapat diintegrasikan ke dalam materi IPA, serta menunjukkan bahwa pemanfaatan jenis tumbuhan dijadikan sebagai pewarna alami ini merupakan konsep sains yang berasal dari pengetahuan asli masyarakat kampung Ciwaringin.

\section{Identifikasi warna yang dihasilkan dari beberapa jenis tumbuhan}

Dari beberapa jenis tumbuhan ini menghasilkan warna yang berbeda-berbeda pula (Tabel 1), dan warna yang dihasilkan memiliki karakter yang sangat khas. Warna dalam batik ini jika dilihat secara kasat mata tidak terlihat menarik, karena warna yang dihasilkan nampak beladus seperti kain yang sudah usang. Namun hal ini menjadi sebuah karakter warna khas yang dihasilkan dari bahan alami. Adapun warna yang terlihat tampak tegas seperti kuning atau oranye ini sangat dipengaruhi oleh larutan fiksasi yang digunakan pada saat proses pewarnaan.

Terdapat beberapa faktor yang mempengaruhi perbedaan terhadap warna yang dihasilkan dari setiap bahan, bahkan dalam satu bahan warna alam dapat menghasilkan berbagai warna yang berbeda. Faktor tersebut adalah metabolit sekunder tumbuhan itu sendiri, serta dipengaruhi oleh jenis larutan fiksasinya yang dapat dilihat pada gambar 4.

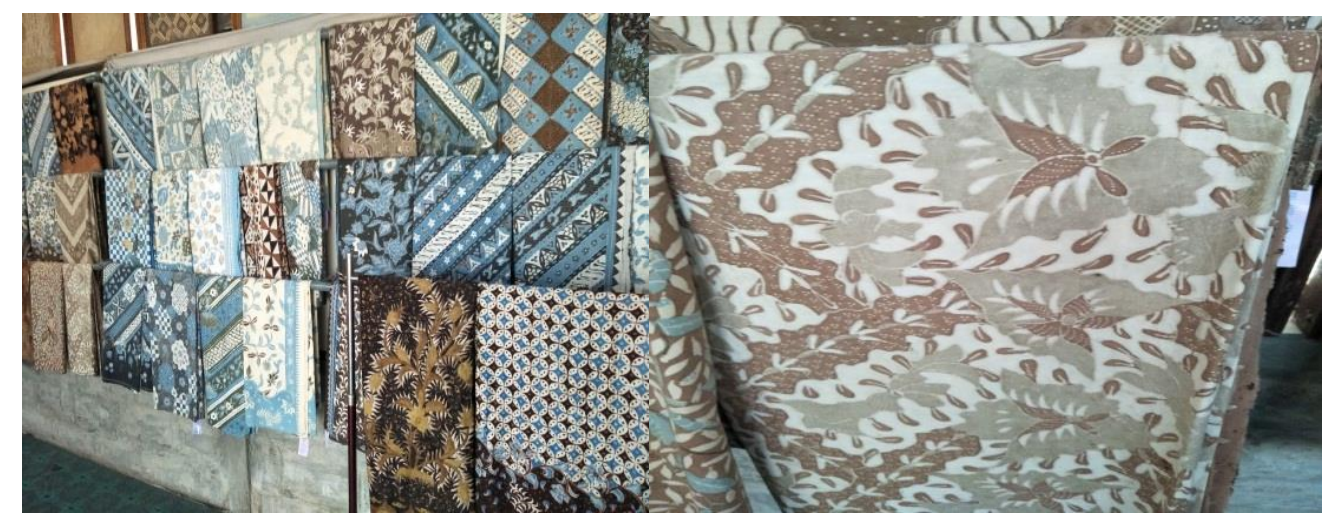

Gambar 4. Warna Ciri Khas Batik Tulis Ciwaringin

Dari hasil wawancara mendalam kepada salah satu tokoh masyarakat kampung Ciwaringin bapak Sholihin (65 Tahun), warna yang paling sulit dihasilkan dari pewarna alami ini adalah warna merah. Menurut hasil percobaan masyarakat setempat pada akar tumbuhan mengkudu dihasilkan warna merah, namun tidak bisa digunakan sebagai pewarna 
alami dalam produksi batik tulis ini, dikarenakan bagian akar ini jika diambil akan mengganggu terhadap pelestarian jenis mengkudu ini.

\section{Penggunaan Larutan Fiksasi Terhadap Warna Batik}

Selain mahasiswa mengeksplor berbagai macam sumber daya alam hayati yang digunakan disana, para mahasiswa juga melakukan eksperimen mewarnai batik dari satu bahan tetapi difiksasi dengan dua macam larutan fiksasi yang berbeda yaitu tawas (Kal $\left.\left(\mathrm{SO}_{4}\right) 2\right)$, dan kapur $(\mathrm{Ca}(\mathrm{OH}) 2)$, maka menghasilkan warna yang berbeda (gambar 5).

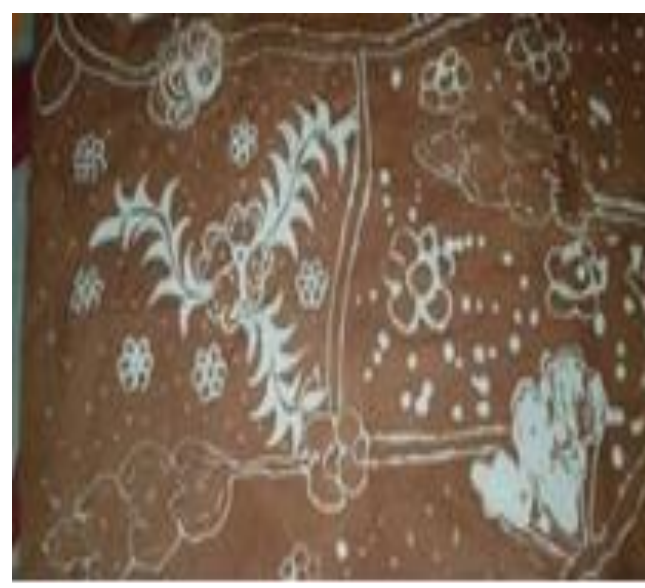

Tingi dengan fiksasi Kapur

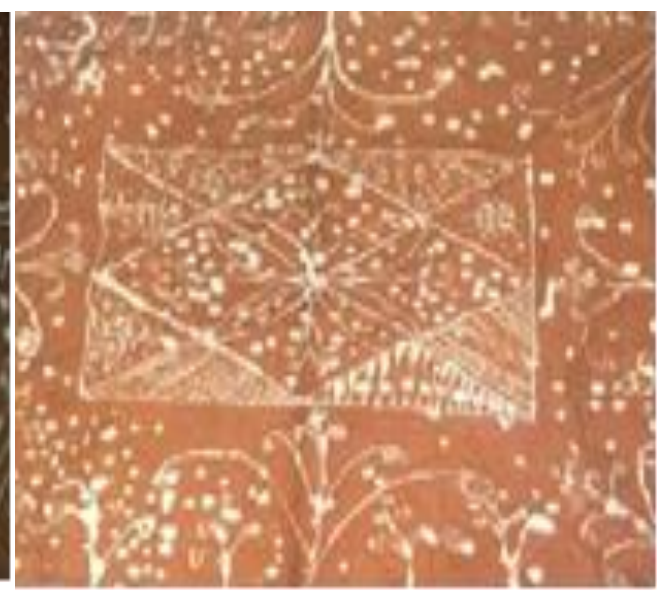

Tingi dengan fiksasi Tawas

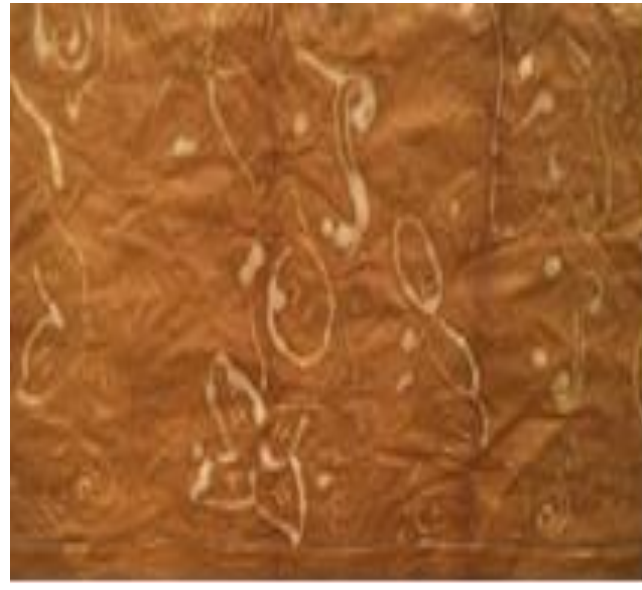

Tegeran dengan fiksasi Kapur

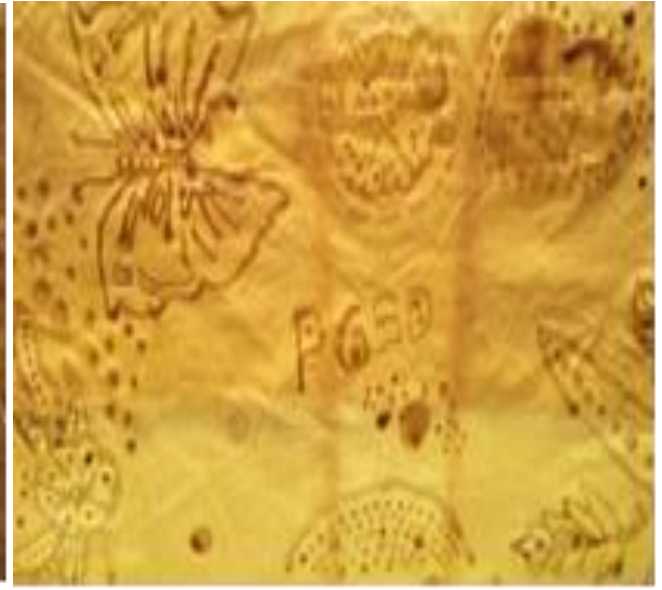

Tegeran dengan fiksasi Tawas 

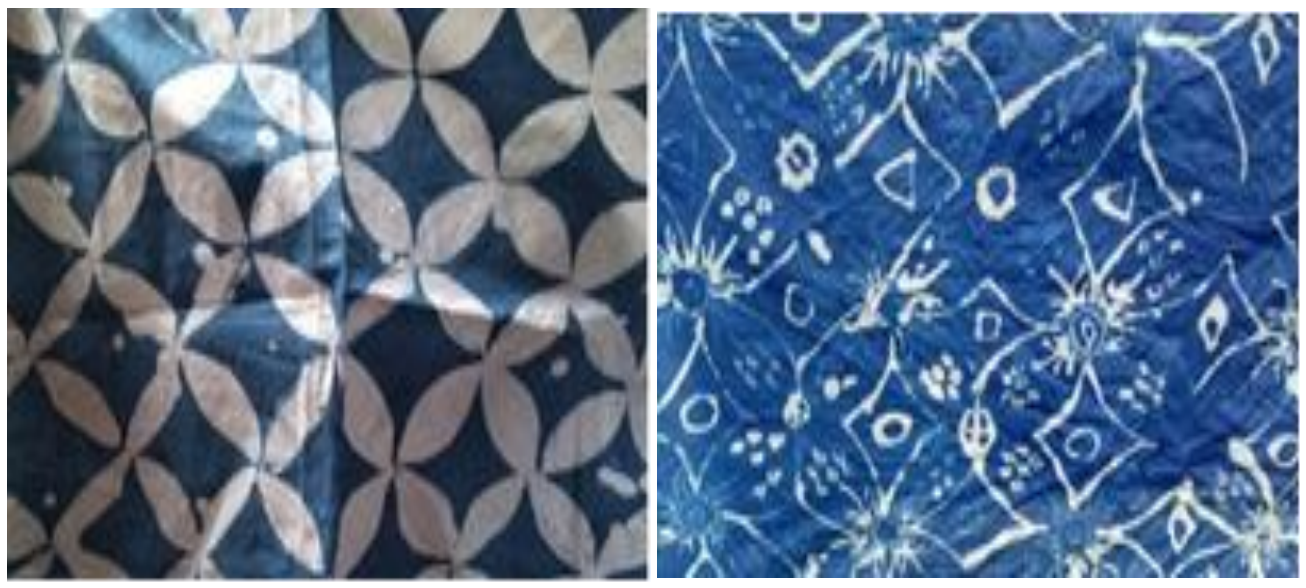

Indigo dengan fiksasi Cuka

Gambar 5. Karya Batik Mahasiswa PGSD menggunakan Pewarna alami dengan larutan Fiksasi yang berbeda

Proses fiksasi merupakan sains ilmiah, sedangkan sains asli budaya masyarakatnya (Indigineous knowledge) adalah proses “pengunci”. Proses fiksasi/ pengunci ini menggunakan berbagai macam larutan fiksasi yaitu larutan yang akan menguatkan warna dan mengubah zat warna alam sesuai dengan jenis logam yang mengikatnya. Larutan fiksasi yang lazim digunakan oleh para pengrajin batik Ciwaringin, adalah tawas $\left(\mathrm{Kal}\left(\mathrm{SO}_{4}\right) 2\right)$, kapur $(\mathrm{Ca}$ $(\mathrm{OH}) 2)$, dan tunjung $\left(\mathrm{FeSO}_{4}\right)$. Sedangkan untuk indigo (tom) para pengrajin batik ini menggunakan cuka. Larutan fiksasi ini merupakan bahan sintetis bukan berasal dari bahan alami atau sumber daya alam hayati Menurut hasil wawancara dengan salah satu pengrajin batik bapak H. Fatoni, menyatakan bahwa sangat kesulitan jika proses pengunci menggunakan bahan alami kendalanya dalam segi ekonomi, seperti contoh gula merah, dan jeruk nipis, jika dijadikan larutan fiksasi membutuhkan biaya yang mahal hingga saat ini belum ada penelitian untuk bahan larutan fiksasi dari bahan alami yang lebih ekonomis.

\section{E. Rekonstruksi pengetahuan sains masyarakat}

Rekonstruksi pengetahuan asli budaya masyarakat ini merupakan bagian penting dari pembelajaran berbasis kearifan lokal. Menurut Parmin (2017) rekonstruksi merupakan penerjemahan dari budaya yang ada di masyarakat dengan konsep-konsep sains yang ada. Sains yang ada yang dimaksud yaitu sains asli atau pengetahuan asli (Indigineous knowledge), untuk mendapatkan sebuah pengetahuan asli (Indigineous knowledge) maka para mahasiswa melakukan eksplorasi melalui observasi dan wawancara secara langsung budaya pada masyarakat kampung Ciwaringin terkait pembuatan batik tulis dengan menggunakan pewarna alami yang menggunakan sumber daya alam hayati lokal yang ada di wilayah Cirebon. 
Para mahasiswa merekonstruksi pengetahuan masyarakat terkait dalam proses tahapan pembuatan pewarna alami dan pembuatan batik yang diterjemahkan dalam konsep sains ilmiah. Salah satu contoh dalam tahapan pembuatan batik yaitu tahapan mengunci warna (konsep sains pengetahuan asli masyarakat), mengunci warna diterjemahkan dalam konsep sains yaitu proses fiksasi (konsep ilmiah), dimana proses tersebut proses pengikatan warna dengan cara direndam dengan larutan fiksasi yang berbeda-beda terhantung kandungan materi yang ada dalam pewarna alami tersebut.

Selain merekonstruksi tahapan dalam proses pembuatan batik, juga merekonstruksi pewarna alami yang digunakan. Mahasiswa melakukan rekonstruksi ini melalui eksplorasi dan kajian pustaka, serta dari beberapa artikel penelitian yang telah dilakukan terkait bahan alami yang digunakan dalam pewarnaan batik Ciwaringin. Berikut hasil rekonstruksi bahan warna alam oleh mahasiswa PGSD Unswagati Cirebon dapat di lihat pada tabel 1 berikut:

Tabel 1. Rekonstruksi Sains Asli dan Sains Ilmiah Tentang Bahan Warna Alam

\begin{tabular}{|c|c|c|c|c|}
\hline No & $\begin{array}{c}\text { Bahan warna } \\
\text { alam }\end{array}$ & $\begin{array}{l}\text { Warna } \\
\text { yang } \\
\text { dihasilkan/ } \\
\text { sains asli }\end{array}$ & Sains Ilmiah & $\begin{array}{c}\text { Daerah } \\
\text { asal }\end{array}$ \\
\hline 1 & $\begin{array}{l}\text { Daun } \\
\text { Indigo/tan.Nila } \\
\text { (Indigofera } \\
\text { tinctoria) }\end{array}$ & Biru & $\begin{array}{l}\text { Mengandung glukosida indikan. Yang } \\
\text { dihidrolisis oleh asam mineral, } \\
\text { mengubah indikan menjadi indoksil } \\
\text { dan glukosa. Indoksil dapat dioksidasi } \\
\text { menjadi indigo dengan warna biru } \\
\text { (Adalina, dkk 2010) }\end{array}$ & Solo \\
\hline 2 & Kulit Mahoni & $\begin{array}{l}\text { Coklat } \\
\text { agak tua }\end{array}$ & $\begin{array}{l}\text { Terdapat kandungan kimia berupa } \\
\text { flavoida yang merupakan pigmen } \\
\text { penghasil warna kuning-coklat } \\
\text { (Kasmudjo, probo, dan widowati, } \\
\text { 2010) }\end{array}$ & Cirebon \\
\hline 3 & Kulit kayu manga & $\begin{array}{l}\text { Coklat } \\
\text { muda }\end{array}$ & $\begin{array}{l}\text { Mengandung senyawa Mangiferine } \\
\text { yang menghasilkan warna coklat } \\
\text { (Wilujeung, 2010) }\end{array}$ & Cirebon \\
\hline 4 & $\begin{array}{ll}\text { Kulit } & \text { Buah } \\
\text { Rambutan } & \end{array}$ & $\begin{array}{l}\text { Coklat } \\
\text { muda }\end{array}$ & $\begin{array}{l}\text { Mengandung flavonoid, tannin dan } \\
\text { saponin (Dalimartha, 2003) }\end{array}$ & $\begin{array}{l}\text { Cirebon, } \\
\text { Subang }\end{array}$ \\
\hline 5 & Kulit Jengkol & Coklat oker & & Cirebon \\
\hline 6 & Kulit Manggis & $\begin{array}{l}\text { Coklat } \\
\text { muda }\end{array}$ & $\begin{array}{l}\text { Kulit buah manggis mengandung } \\
\text { pigmen antosianin yang berperan } \\
\text { penting dalam pewarnaan krem } \\
\text { (Hidayat. N, Saati, 2006) }\end{array}$ & $\begin{array}{l}\text { Cirebon, } \\
\text { tasik, } \\
\text { Ciamis }\end{array}$ \\
\hline 8 & $\begin{array}{l}\text { Kulit } \\
\text { Nangka }\end{array}$ & $\begin{array}{l}\text { Kuning } \\
\text { Muda }\end{array}$ & $\begin{array}{l}\text { Tannin yang terkandung di dalam kulit } \\
\text { kayu nangka menghasilkan warna } \\
\text { (Corbman, 1985) }\end{array}$ & Cirebon \\
\hline
\end{tabular}

Sumber: Hasil Eksplorasi dan Kajian Artikel Ilmiah Mahasiswa PGSD Unswagati 2017

Eksplorasi ini sesuai dengan hasil penelitian Kidman dan Abrams (2013) yang mengungkapkan bahwa di dalam sebuah pengetahuan masyarakat terdapat pengetahuan sains 
yang harus dikaji dan dipelajari. Bahkan rekonstruksi ini untuk penelitian berikutnya dapat diuji secara laboratorium terkait metabolit sekunder yang terkandung di dalam beberapa sumber daya alam hayati yang digunakan sebagai pewarna alami di batik tulis Ciwaringin. Melalui rekonstruksi pengetahuan asli pada masyarakat ini akan dihasilkan konsep-konsep sains, sehingga para mahasiswa mampu memperdalam penguasaan konsep sains bahwa setiap bahan sumberdaya alam hayati dari mulai akar, batang, daun bunga serta biji dan buah bahkan limbah kulit buahnya pun memiliki kandungan yang bermanfaat dalam kehidupan.

Hal ini menunjukkan bahwa budaya yang telah melekat didalam bangsa kita terutama masyarakat desa Ciwaringin Cirebon, memiliki nilai-nilai yang sangat bermanfaat bagi kehidupan manusia. Selain itu, diharapkan dapat menumbuhkan karakter positif seperti menghargai budaya sebagai kearifan lokal serta melestarikan budaya tersebut yang berimplikasi terhadap konservasi sumber daya alam sekitar. Menurut Suastra (2010), Parmin, 2017) menyebutkan bahwa pembelajaran sains yang akan datang perlu diupayakan agar ada keseimbangan antara pengetahuan sains itu sendiri dengan penanaman sikap-sikap ilmiah, serta nilai-nilai kearifan lokal yang ada dan berkembang di masyarakat. Pernyataan ini menunjukkan betapa pentingnya kearifan lokal dalam pembelajaran sains, serta mahasiswa diharapkan memiliki kecintaan terhadap pengetahuan asli sebagai bagian dari budaya bangsa yang harus di lestarikan dan menguatkan pola pendidikan yang berorientasi pada kecintaan terhadap keseimbangan lingkungan.

\section{F. Upaya Peningkatan Konservasi Lingkungan}

Kegiatan ini membentuk sikap peduli terhadap pelestarian budaya membatik Ciwaringin dengan menggunakan pewarna alami. Hasil presentasi yang dikemukakan oleh beberapa kelompok mahasiswa bahwa budaya membatik Ciwaringin harus dipertahankan, karena hasil eksplorasi yang telah dilakukan mengungkap kebenaran secara langsung keterkaitan pengetahuan masyarakat dengan pengetahuan sains di sekolah dalam pemanfaatan sumber daya alam lokal di Cirebon. Hal ini sesuai pendapat Lowan (2016) yang menyatakan bahwa melalui eksplorasi secara langsung dengan budaya masyarakat tersebut, maka indigenous knowledge atau pengetahuan sains masyarakat dapat diketahui kebenarannya. Sehingga pembelajaran berbasis kearifan lokal ini diharapkan meningkatkan kesadaran akan pentingnya budaya lokal serta konservasi sumber daya alam hayati di wilayah Cirebon. 


\section{SIMPULAN}

Berdasarkan hasil penelitian yang telah diuraikan di atas dapat disimpulkan bahwa terdapat berbagai jenis tumbuhan lokal yang digunakan sebagai pewarna alami di batik ciwaringin, baik dari akar, batang/kulit kayu, daun, bunga, dan buah serta limbah kulit buahnya. Kemudian melalui eksplorasi pengetahuan sains masyarakat (Indigineous knowledge) dihasilkan menjadi sebuah konsep-konsep sains, sehingga para mahasiswa mampu memperdalam pemanfaatan sumber daya alam (konsep sains) secara nyata dan mengubah persepsi pengetahuan asli masyarakat yang terkesan sebagai pengetahuan budaya warisan saja menjadi sebuah pengetahuan ilmiah yang dapat dipertanggungjawabkan. Pembelajaran sains berbasis kearifan lokal ini dapat menumbuhkan kecintaan terhadap pengetahuan asli masyarakat sebagai bagian dari budaya bangsa yang berimplikasi terhadap konservasi sumber daya alam sekitar dan keseimbangan lingkungan. Selain itu, budaya masyarakat kampung batik Ciwaringin tersebut juga dapat diintegrasikan dengan materi IPA di sekolah.

\section{DAFTAR PUSTAKA}

Arfianawat, S., Sudarmin, dan Sumarni, W. (2016). Model Pembelajaran Kimia Berbasis Etnosains untuk Meningkatkan Kemampuan Berpikir Kritis Siswa. Jurnal Pengajaran MIPA, 21(1), 46-51.

Casta. (20150. Batik Ciwaringin dalam Pesona Warna Alam. Cirebon: Dinas Kebudayaan, Pariwisata, Pemuda dan Olahraga Kabupaten Cirebon

Handayani, P.A. dan Mualimin, A.A. (2013). Pewarna Alami Batik dari Tanaman Nila (Indigofera) dengan Katalis Asam. Jurnal Bahan Alam Terbarukan, 2(1), 1-6.

Kidman, J., Yen, C., and Abrams, E. (2013). Indigenous Student Experiences of the Hidden Curriculum in Science Education: A Cross Naational Study in New Zealand and Taiwan. International Journal of Science and Mathematics Education, 11(1), 43-64.

Lowan, G. (2016). Gateway to Understanding: Indigenous Ecological Activism and Education in Urban, Rural, and Remote Context. Journal of Cultural Studies of Science Education, 11(10), 46-59.

Palmer, J., Neal, P. (1994). The Handbook of Environmental Education. London: Routledge

Parmin, Sajidan, Ashadi, dan Sutikno. (2017). Etnosains: Kemandirian Kerja Ilmiah Dalam merekonstruksi Pengetahuan Asli Masyarakat Menjadi Pengetahuan Ilmiah. Semarang: Swadaya Manunggal.

Ramadhania, D., Kasmudjo, dan Probo, P.S. (2010). Pengaruh Perbedaan Cara Ekstraksi dan Bahan Fiksasi Bahan Pewarna Limbah Serbuk Kayu Mahoni (Swietenia macrophylla King) Terhadap Kualitas Pewarnaan Batik. Prosiding Nasional Masyarakat Peneliti Kayu Indonesia Indonesia (MAPEKI), 1(1), 414-423.

Republik Indonesia. (2014). Undang-Undang No.57 Tahun 2014 tentang Kurikulum 2013 Sekolah Dasar/ Madrasah Ibtidaiyah. Lembaran Negara RI Tahun 2014. Sekretariat Negara. Jakarta. 
Suastra, I. W. (2005). Merekonstruksi Sains Asli (Indigenous Science) dalam Upaya Mengembangkan Pendidikan Sains Berbasis Budaya Lokal di Sekolah. Jurnal Pendidikan dan Pengajaran, 38(3), 377-396.

Sudarmin, Pujiastuti, E.S. (2015). Scientific Knowledge Based Culture and Local Wisdom in Karimunjawa for Growing Soft Skills Conservation. International Journal of Science and Research, 4(9), 598- 604.

Sudiana, I. M., dan Surata, I.K. (2010). IPA Biologi Terintegrasi Etnosains Subak untuk Siswa SMP: Analisis tentang Pengetahuan Tradisional Subak yang Dapat Diintegrasikan dengan Materi Biologi SMP. Jurnal Suluh Pendidikan, 8(2), 43-51.

Tresnawati, N and Wariin, I. (2017). Elementary School Science Learning Through Ethnoscience Approach in Mangrove Forest Conservation toward Conservation Literacy. The $4^{\text {th }}$ International Conferenc On Research, Implementation, And Education Of Mathematics And Science (4th ICRIEMS) Proceedings Yogyakarta State University, 4(1), SE31-SE36. 